Original Research

\title{
Energy Storage and Installed Wind Capacity Requirements for the Substitution of Fossil Fuels in the Electricity Generation Sector
}

Efstathios E. Michaelides *

Dept. of Engineering, TCU, Fort Worth, TX, 76132, USA; E-Mail: E.Michaelides@tcu.edu

* Correspondence: Efstathios E. Michaelides; E-Mail: E.Michaelides@tcu.edu

Academic Editor: Aritra Ghosh

Special Issue: Progress of Wind Energy Technology and Its Maintenance

Journal of Energy and Power Technology

2021, volume 3 , issue 3

doi:10.21926/jept.2103040
Received: April 19, 2021

Accepted: September 07, 2021

Published: September 10, 2021

\begin{abstract}
The impending adverse effects of Global Climate Change encourages the substitution of fossil fuels with non-carbon sources for electricity generation. However, while fossil fuel power plants may generate electric power at demand, the most abundant renewable energy sources-wind and solar-are intermittent or periodically variable. This necessitates the development of adequate energy storage at the utility/grid level. Using actual data for the hourly energy demand in the ERCOT electricity grid, this study examines the electricity supplydemand equilibrium and determines the necessary energy storage capacity for the substitution, first, of the coal power plants and, secondly, of all the fossil fuel power plants. The calculations show that, if the natural gas, intermediate-load power plants continue to be available, all coal units may be substituted with wind farms without the need for energy storage. When all the fossil fuel units are to be substituted, significant energy storage capacity is required, approximately 45.3 million $\mathrm{m}^{3}$. The calculations also show that the further development of nuclear energy and additional solar energy units reduce the requirements for energy storage and, also lessen the energy dissipation in the storage-recovery process.
\end{abstract}

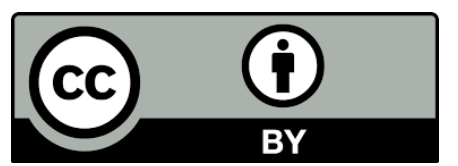

(c) 2021 by the author. This is an open access article distributed under the conditions of the Creative Commons by Attribution License, which permits unrestricted use, distribution, and reproduction in any medium or format, provided the original work is correctly cited. 


\section{Keywords}

Wind energy; sustainability; renewable energy; supply-demand of electricity; carbon dioxide emissions; substitution of coal, substitution of fossil fuels

\section{Introduction}

The continuously increasing emissions of carbon dioxide gas $\left(\mathrm{CO}_{2}\right)$ in the atmosphere have significantly increased the concentration of this gas-from $280 \mathrm{ppm}$ before the industrial revolution to more than $410 \mathrm{ppm}$ in 2020-and have ushered a global climate change (GCC) that will adversely affect all economic activities of mankind as well as entire ecosystems. A rational and feasible strategy to alleviate the effects of GCC is to significantly decrease the global $\mathrm{CO}_{2}$ emissions.

Approximately $40 \%$ of the primary energy sources, globally, are used for the generation of electricity and $64.2 \%$ [1] of the electricity is currently generated by fossil fuels-primarily from coal, natural gas and petroleum-in power plants. Substituting the fossil fuels (particularly coal) with renewable energy sources (RES) for the generation of electricity, would result in significant $\mathrm{CO}_{2}$ emissions reduction. A modest increase of the nuclear (another non-carbon primary energy source) generation capacity would also assist with the decarbonization of the electricity sector $[2,3]$.

One of the major impediments for the substitution of fossil fuels with RES for electricity generation is the demand-supply mismatch and the lack of energy storage infrastructure. All the electric power demand in an electricity grid is almost instantaneously matched by the generation of electric power in the units that generate electric energy and supply the grid. At present, base-load units-primarily coal and nuclear units that operate with steam cycles-and intermediate or peak units-primarily natural gas and diesel units that operate with gas cycles-supply most of the electric power in electricity grids, globally [4]. The power production from the base-load coal and nuclear units may be reduced to approximately $80 \%$ of their rated capacity by steam throttling, but reductions below this level are detrimental to the operating equipment. Frequent interruptions and substantial power reduction in steam power plants would impair or damage their machinery. Because of this, nuclear and coal-fired power plants operate as base-load units and continuously operate to supply power to the electricity grids throughout the globe. Any power demand fluctuations are primarily met by gas cycle units and, if available, by hydroelectric units $[4,5]$.

A significant problem with the renewable solar and wind energy is that they are not always available when power is demanded by the consumers of the electricity grid. For example, during the evening of July 17, when the electricity demand is very high because of the continuous operation of air-conditioning systems in Texas and similar regions everywhere in the world, there is no solar irradiance to generate power in photovoltaics, and at that hour, the feeble winds are insufficient to generate enough electricity to satisfy the demand. For this reason, significant energy storage in the electric grid becomes necessary for any transition to RES for electricity generation.

A second and related problem with the RES, and especially with solar energy, is that when a region generates a high fraction of the total annual electric energy by solar energy, the solar installations generate significant power during the early daylight hours (e.g. between 9 am and noon) but the electric power demand is not high because the ambient temperature is moderate and the air-conditioning demand is low. The high level of power generation from the PV systems in 
combination with the lower electricity demand in the grid, causes the demand from the non-solar units to significantly drop. Since the base-load units that operate on Rankine cycles must continuously produce power, there is excess power in the grid, which must either be stored (again, the need for significant, utility-level storage) or dissipated and waisted. The same demand-supply mismatch is observed with wind power during windy nights in the spring and autumn, when the electricity demand is low, and the wind-generated power is at the installed capacity level. This supply-demand mismatch phenomenon has been well-documented for solar installations and is popularly referred to as the as the $U$-curve or the duck curve of electric power supply $[6,7]$.

Figure 1 illustrates the supply-demand mismatch during the 24 hours of January 22, 2019 in the Electric Reliability Council of Texas (ERCOT) system, if the wind power units in the region generated $30 \%, 40 \%$ and $50 \%$ of the total annual energy demand in the electricity grid. The Figure depicts the hour of the day ( 0 hour is at midnight) versus the power demand from non-wind sources. The contribution of the base load nuclear power plants, which may not be shut down, and the total electric power demand in the grid are also shown. It is observed that demand for the non-wind power plants dips below the nuclear supply in the early morning hours when $40 \%$ of the total annual energy is generated by wind. The demand of the non-wind power plants dips even below zero for most of the 24-hour period when the wind units generate $50 \%$ of the total electricity. The dip during these periods of time signifies that the wind units generate a large amount of energy, which is higher than the demand by the consumers. This implies that the excess energy (the dip below the nuclear supply level) generated by the wind on that day must either be stored or otherwise dissipated in the grid and wasted.

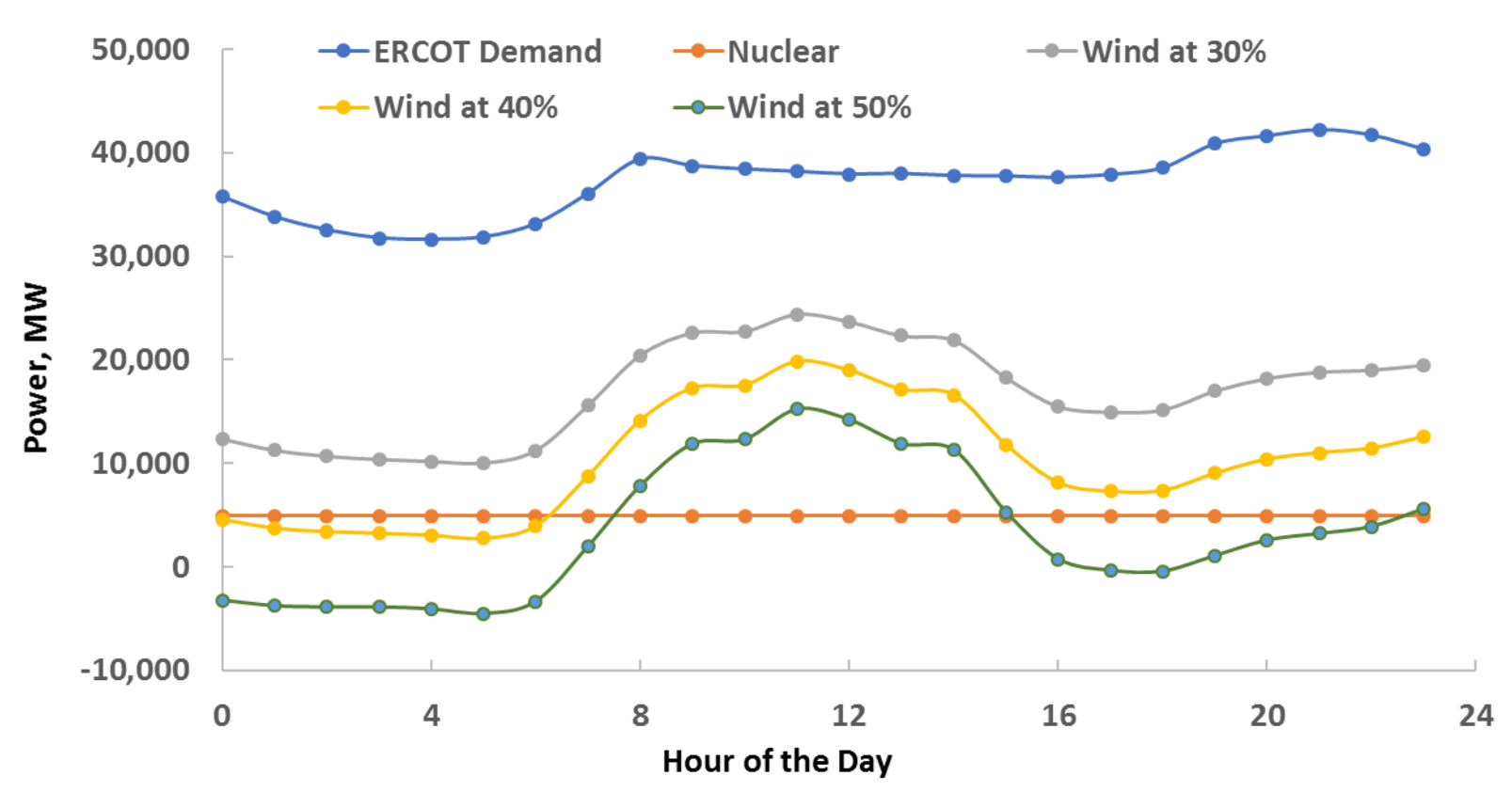

Figure 1 Increasing the annual wind energy generation of electricity leads to demandsupply mismatches that cause significant power surpluses a times.

The demand-supply mismatch, which may persist for most of the time during a year, necessitates the development and application of utility-level energy storage systems that supply the electric power when the RESs are inadequate to satisfy the demand [8, 9]. A case study for France [10]-a country that generates approximately $80 \%$ of its electricity from nuclear reactors-concluded that 
the higher penetration of renewables, would significantly alter the shape of hourly demand curve and that other options (e.g. energy storage or power dissipation/waste) will be needed for the reliable operation of the French national grid. Another study pertaining to a combination of RES and nuclear reactors suggested a hybrid system of High Temperature Gas Reactors and renewable energy for grid stability and improved reliability [11]. A more recent study calculated the utility-level energy storage needs for the substitution of fossil power plants with RES in an entire national grid and the beneficial effect of increased nuclear contribution to the generation of electricity [12].

The generation of mechanical power from wind power is a mature technology that goes back to the sailboats and the windmills. Wind power for the generation of electricity commenced in the middle of the $20^{\text {th }}$ century and significantly accelerated since the 1990s [13]. In the recent years research on wind power generation has concentrated primarily on topics related to the optimization of wind turbine operations; materials for stronger turbine blades; the potential for electric power generation globally; the use of satellite data for the surface wind predictions and reduction of wind power generation uncertainty; and the effect of climate change on the wind power in specific regions of the earth [14-19].

This paper aims at presenting a realistic scenario for the decarbonization and transformation of the electricity generation sector with the substitution with wind power, first, of the coal power plants and, secondly, of all the fossil fuel power plants in a large electricity grid, ERCOT, which serves most of the State of Texas. ${ }^{1}$ Based on the hourly power demand of the electricity grid, calculations are performed to determine the needed installed capacity of wind units, the required energy storage capacity for the grid to meet the power demand, and the annual energy dissipation the storage-regeneration processes entail for the grid.

\section{The ERCOT Electricity System}

The ERCOT system manages the production and distribution of electricity to more than 26 million people in the State of Texas, including $95 \%$ of the businesses in the State. Because of the high use of electric energy in the State, the size and generating capacity of the grid is equivalent to the national grid of a very large economy: In 2017 the ERCOT system generated and distributed 358.5 TWh to its customers. This is higher than the electricity generated and supplied by the electricity grids of Italy (314.9 TWh) and the entire UK grid (327 TWh) in 2017 [20]. In 2019 the generation facilities in the grid generated 384.5 TWh. The peak power demand during 2019 was 74,541 MW in the afternoon of August 12 (the very hot weather induced high air-conditioning use) and the minimum demand was $27,656 \mathrm{MW}$, in the early morning hours of April 20. The continental climate of Texas with the high use of air-conditioning during the summers is the reason for the high ratio (2.7) of maximum to minimum power demand.

A diverse mixture of electricity generating units-including nuclear, coal, gas, solar, hydroelectric and wind-supply the needed electric power to the ERCOT grid. Figure 2 depicts the primary energy sources (the fuel mix) that generated the demanded electric energy during the period 2006-2020 [21]. The energy sources labelled as "other" primarily include PV solar (currently supplying $2.3 \%$ of the total annual electric energy), a very small amount of biomass, and a small amount of energy imported from Mexico.

\footnotetext{
${ }^{1}$ It was announced by the Biden administration, in April 2021, that “...the United States has set a goal to reach 100 percent carbon pollution-free electricity by $2035 . "$
} 


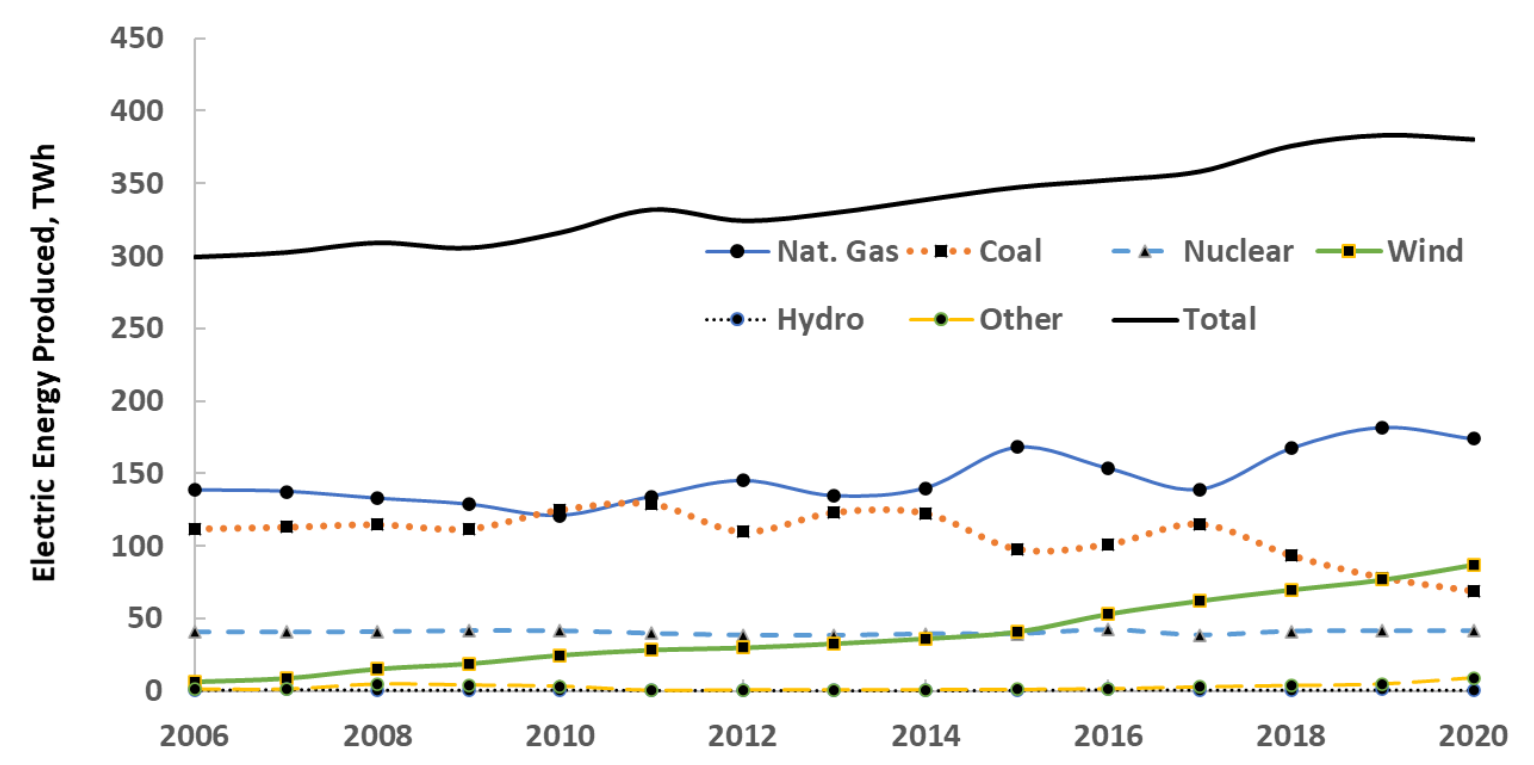

Figure 2 Primary energy sources that supplied electric energy to ERCOT in the period 2006-2020.

Several important observations may be made from the data depicted in Figure 2:

1. The fossil fuels, natural gas and coal, supplied most of the electric energy. However, the coal contribution has been continuously falling in the last six years-a trend consistent with other grids in the OECD to significantly reduce and, perhaps, eliminate coal from the electricity generation mix.

2. The contribution of wind power to electricity generation dramatically increased in the period covered by the Figure. In 2020 wind generated 87 TWh of electricity, a little more than $20 \%$ of the total. This quantity of energy is significantly more than the energy generated by the nuclear power plants and slightly more than that generated by coal.

3. Solar energy does not yet contribute much to the production of electricity in the grid. In 2020 the solar PV units contributed approximately $2.3 \%$ of the total.

\section{Governing Equations}

The decarbonization of the electricity generation sector will happen with the substitution of fossil fuels using RES and, perhaps, nuclear energy. In order to achieve decarbonization, the wind and solar generating capacities in the ERCOT region will have to significantly increase. Regarding energy storage, which becomes necessary with the introduction of more wind and solar units, Pumped Hydro Systems (PHS), Compressed Air Energy Systems (CAES), and Hydrogen Systems (HS) are the options for utility-level energy storage [7]. The entire geographic region of Texas does not have locations at the high elevation, where PHS may be built. It also lacks underground caverns with adequate capacity for the CAES to operate. In addition, CAES facilities in the USA have proven to be expensive and inadequate for very large quantities of energy storage. Because of their current drift that leads to self-discharge, battery storage systems are not recommended for the seasonal storage of energy, e.g. from spring, when wind power is plentiful, to summer, when the high air-conditioning 
usage significantly increases the demand for power. Under these circumstances, HS becomes the optimal (perhaps the only) available option for significant energy storage in the ERCOT grid.

In a decarbonized electricity industry with hydrogen storage, when the wind, solar, and nuclear power plants generate more power than the immediate demand, the excess energy is stored locally in tanks holding pressurized hydrogen. When the demand exceeds the supply of the energy sources, the stored energy is used to satisfy the power demand. Hydrogen may be produced by electrolysis and stored at high pressure. This technology is mature, with several automobile models currently operating with hydrogen tanks at pressures as high as 700 bar [22]. Fuel cells, which are direct energy conversion devices and very efficient, are used to convert the stored energy in hydrogen to electricity. Of course, the storage-regeneration process entails energy losses (dissipation), which reduce the energy that becomes available to the electricity grid. The dissipation and the round-trip efficiency of the storage may be calculated from the efficiencies of the pertinent processes [23, 24].

When the fossil fuel power plants are substituted by wind turbines, the electric energy generated at any given hour of the year depends on the characteristics of the wind turbines [25-27]. The currently available wind turbines generate zero energy at very low wind velocities-typically in the range $0-3 \mathrm{~m} / \mathrm{s}$. They generate energy that is proportional to the available energy of the wind at moderate velocities-typically in the range 3-12 m/s-according to the expression:

$$
E_{W P i}=\frac{\pi}{8} \eta_{W i} D^{2} \rho V^{3} t
$$

where $\eta_{w i}$ is the efficiency of the wind turbine; $D$ is the wind turbine diameter; $\rho$ is the density of the air; and $V$ is the instantaneous air velocity at the hub of the turbine.

At the higher wind velocities-typically in the range $12-26 \mathrm{~m} / \mathrm{s}$-the current types of the wind turbines generate power approximately equal to their rated power. The wind turbines are "feathered" and produce zero energy when the wind velocities are extremely high-typically above $26 \mathrm{~m} / \mathrm{s}[7,25,26]$.

Approximately $27,000 \mathrm{MW}$ of wind power are currently in operation within the ERCOT region. There is significant accumulated experience with wind energy and sufficient data to conduct simulations in the region for increased wind capacity. For the computations of this study the average hourly production by wind turbines in the entire region, per MW installed in the years 2018 and 2019, was calculated and used on a prorated basis to determine the electric energy that would be generated with the increased installed wind capacity. It must be noted that, within the State of Texas, there is a multitude of locations where new wind installations can be built with similar power generation factors as the ones currently in operation. This justifies prorating the current wind power generation. Under a regime when existing nuclear power plants and RESs generate power, the total electric energy generation during an hour of the year, $i$, is equal to the sum of the energy generated by the nuclear, wind, hydroelectric, and solar installations:

$$
E_{P i}=E_{W P i}+E_{S P i}+E_{H P i}+E_{N P i}
$$

The hourly electric energy demand for an entire year is published by ERCOT and is known for a series of years [21]. Currently, there are no plans to increase the capacity of the nuclear and hydroelectric units. For this reason, it was stipulated that the nuclear, and hydroelectric power plants will continue generating base load power at the same levels they currently generate and the 
remaining part of the electricity demand will be supplied by a combination of wind and solar energy and, when necessary, by stored energy. When the energy generation of all the power installations exceeds the demand in a given hour of the year-as it often happens during strong wind time periods at nighttime and during cloudless and high insolation days during the morning hours in the springthe excess generated electricity is stored as hydrogen to be used at another time period. When the generated power during an hour is not sufficient to cover the energy demand, the stored energy supplies the deficit. The quantity of energy that becomes available for storage or generated from the storage, $\delta E_{s i}$, during a given hour is equal to the difference between the hourly generation and demand:

$$
\delta E_{S i}=E_{P i}-E_{D i}
$$

Since the electric energy produced is converted at least twice during the storage/recovery process before it can be used by the consumers, and every energy conversion process entails thermodynamic ireversibilities, there is energy dissipation during the processes of: a) electrolysis; b) and hydrogen-to-electricity conversion in fuel cells. These irreversibilities are taken into account by the efficiencies of the electrolysis process, $\eta_{e l}$, and the fuel cells, $\eta_{f c}$. The efficiency of dc-to-ac inverters (if used) is high enough to be lumped in the value of the fuel cell efficiency. Under these conditions the quantity of energy in storage at the hour $(i+1)$ is:

$$
\begin{array}{cc}
E_{S i+1}=E_{S i}+\left(\delta E_{S i}\right) \eta_{e l} & \text { if } E_{P i} \geq E_{D i} \\
E_{S i+i}=E_{S i}-\left(\delta E_{S i}\right) / \eta_{f c} & \text { if } E_{P i}<E_{D i},
\end{array}
$$

where $E_{S i}$ is the energy storage level at hour, $i$. The values of the efficiencies used in this study are: $\eta_{e l}=78 \%$ [23], and $\eta_{f c}=75 \%$ [24].

The annual energy dissipation, due to the energy storage/recovery processes is:

$$
E_{d i s}=\sum_{i=1}^{8760}\left(E_{P i}-E_{D i}\right) \text {. }
$$

It was stipulated in the calculations that, at all hours of the year, the grid storage system must contain enough hydrogen to supply the entire grid for at least one week (168 hours)-a stipulation that significantly improves the reliability of the grid. If there is a local malfunction in the system, a local problem, or adverse weather conditions that severely reduce the quantity of renewable energy produced (e.g. hurricane, tornado, winter freeze), the grid operators will have sufficient time to respond and purchase hydrogen or transport hydrogen from another region. With this stipulation, the stored energy does not diminish to zero at any hour during the year. It was determined that the stored hydrogen minima mostly occurred in October-after the summer air-conditioning peak demand-and that the minimum storage that ensures one week's supply is approximately 8 TWh. The following iteration process is used to solve the system of equations and constraints of this problem:

1. An installed wind capacity (in MW) is assumed.

2. The storage system capacity on the first hour of the year, $E_{s o}$, is also assumed. 
3. During a given hour, the nuclear, solar, and hydroelectric installations generate the same power as in the same hour of the year 2020.

4. The hourly energy surplus or deficit is calculated at every hour of the year.

5. The total quantity of stored energy is calculated at every hour of the year.

6. The stored energy at the end of the year, $E_{S 8760}$, is determined and compared to $E_{S 0}$, at the beginning of the year. If $E_{S 0}<E_{S 8760}$, the wind generation capacity is increased and steps 2-5 are repeated. If $E_{S O}>E_{S 8760}$, the wind generation capacity is decreased, and steps 2-5 are repeated, until $E_{S O}=E_{\$ 8760}$. This iterative process determines the correct value of the installed wind capacity.

The correct value for $E_{S o}$ is obtained by a second iteration. The condition/constraint for this iteration is that, on the day the minimum hydrogen/energy storage occurs, the system still has enough hydrogen to satisfy the entire demand of the grid during the next seven days.

\section{Results and Discussion}

The geography of Texas is ideal for the substantial development of wind power: the state borders the Rock Mountains with a relatively flat, descending terrain (the prairie) that terminates in the Mississippi valley in the east and the Gulf of Mexico in the South. Katabatic flows from the Rocky Mountains develop is strong and steady air currents that may be harnessed to generate electric power. In particular, the Panhandle region of Texas, with strong and relatively consistent winds, is a prime location for the development of wind power. This region has experienced $16 \%$ annual wind power installed capacity in the period 2015-2020. A second region, near the city of Corpus Christi, close to the Gulf of Mexico and the large city of Houston, is also a prime area for the development of onshore as well as offshore wind power. Further expansion of wind power in this area are in the planning and construction stages [28].

Because of the significant wind power potential, it is feasible for ERCOT to achieve the complete substitution of its fossil fuel power plants relying on wind power and energy storage to satisfy the power needs of the grid. The next sections of this paper outline the needed installed power capacity, storage capacity and other parameters that are crucial in achieving this goal. The calculations that follow outline fossil fuels substitution scenaria for electricity generation that satisfy the hourly power demand of the region.

\subsection{Substitution of Coal Power Plants}

The coal power plants in the ERCOT region typically operate as base-load units. Since coal combustion contributes significantly more than natural gas combustion to the $\mathrm{CO}_{2}$ emissions (in $\mathrm{kg}$ of $\mathrm{CO}_{2}$ per $\mathrm{kWh}$ generated), it is reasonable to prioritize the coal generation units in the decarbonization of the grid. Calculations were performed for the substitution of all the coal power plants in the ERCOT region, which currently generate annually 68.5 TWh of electric energy, while the nuclear and solar electricity generation capacity remain at their current levels. Table 1 shows some of the results of these calculations. 
Table 1 Annual electric energy demand and supply, storage needed, and additional wind capacity needed for the substitution of all coal generation units.

\begin{tabular}{ll}
\hline Demand & $380,004,261$ \\
From Wind & $155,458,821$ \\
From Sun & $8,698,546$ \\
From Nuclear & $43,563,480$ \\
Others & $172,595,362$ \\
Dissipation & 311,947 \\
Storage in $\mathrm{m}^{3}$ & $8,719,202$ \\
Installed Wind & 48,700 \\
Additional wind & 21,640 \\
\hline
\end{tabular}

It is observed in Table 1 that with an additional 21,640 MW installed wind capacity it would be possible to substitute all the coal power plants in the State of Texas. In this case, the apparent storage capacity is approximately 8.72 TWh. A moment's reflection, however, proves that thisrather high-storage capacity is principally due to the stipulation that the grid system must have one week's power supply in storage, which at the day of minimum storage is approximately 8.16 MWh. Figure 3 shows the hourly storage level as well as the hourly energy deficit for the entire year when calculations under this stipulation were made.

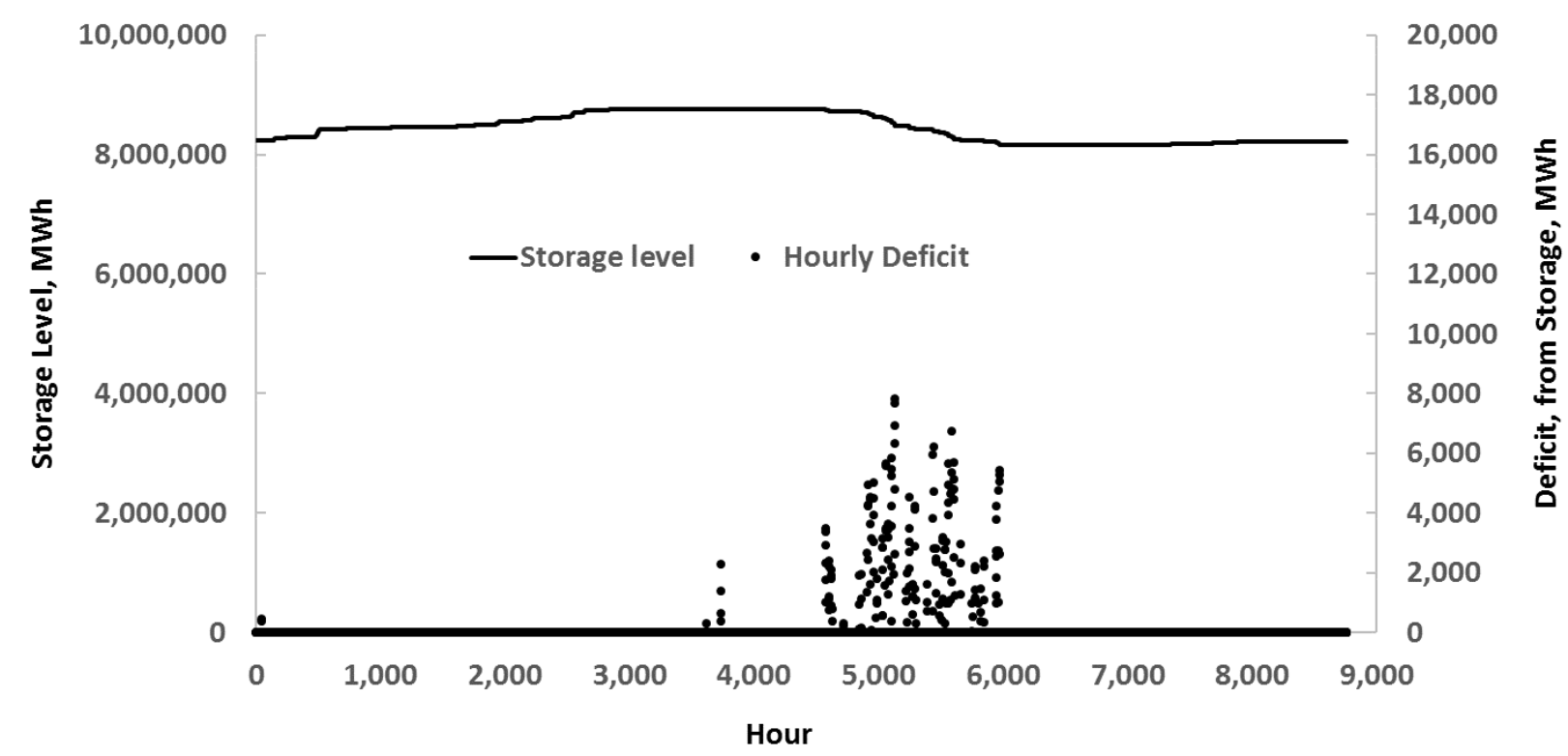

Figure 3 Hourly storage level and hourly energy deficit for the substitution of all coal units with wind power.

It is observed in Figure 3 that energy deficit occurs in only 185 hours during the year $(2.1 \%$ of the total hours) and that the maximum deficit is approximately 8,000 MWh. It is also observed in Table 
1 that, with the addition of the $21,640 \mathrm{MW}$ of wind power, the contribution of the natural gas units would be significantly less than their current contribution. The energy deficit could be easily supplied by the currently existing intermediate- and peak-load natural gas units, if they are maintained and capable to generate power. One may safely conclude from these facts that the substitution of all the coal units in the ERCOR region can be achieved simply by adding 21,640 MW additional wind power and maintaining the currently existing natural gas units to supply all the energy needed.

\subsection{Substitution of All Fossil Fuel Power Plants}

The situation is different when the substitution of the coal as well as the natural gas electricity generation units is contemplated. The natural gas power plants contributed $181.8 \mathrm{TWh}$ in 2019, approximately $47.4 \%$ of the total electricity in the grid. Table 2 shows what would be the parameters and the characteristics of the power generation system for the demand to be met with additional wind installations, while keeping the existing nuclear, hydro, and solar generation capacities at their current levels.

Table 2 Annual electric energy supply, storage needed, and additional wind capacity needed for the substitution of all fossil fuel generation units.

\begin{tabular}{ll}
\hline Demand & $380,004,261$ \\
From Wind & $365,937,933$ \\
From Sun & $8,698,546$ \\
From Nuclear & $43,563,480$ \\
Others & 0 \\
Dissipation & $38,195,698$ \\
Storage in $\mathrm{m}^{3}$ & $46,746,582$ \\
Installed Wind & 114,636 \\
Additional wind & 87,576 \\
\hline
\end{tabular}

It is observed in Table 2 that approximately $88 \mathrm{GW}$ of additional wind capacity and $47 \mathrm{TWh}$ storage capacity would be needed for this large-scale substitution. It appears at first glance that the land area required for this addition would be enormous. A moment's reflection, however, proves that, while the wind turbines are placed at significant distances and wind farms occupy large areas, the actual footprint of the wind turbines is very small and the land within the wind farms remains agricultural and is available for cultivation and animal grazing. The footprint of a $3 \mathrm{MW}$ wind turbine is approximately $30 \mathrm{~m}^{2}$, and the additional $88 \mathrm{GW}$ of wind power will require an area of less than 1 $\mathrm{km}^{2}$ (the land area of Texas is $688,000 \mathrm{~km}^{2}$ ). At present, there is more than $27 \mathrm{GW}$ wind capacity installed in Texas with almost all the land under the turbines used for agricultural purposes. 
Since hydrogen gas is to be stored at $50 \mathrm{MPa}$, the storage capacity in the region is 45.3 million $\mathrm{m}^{3}$. This corresponds to a hydrogen storage tank of approximately $4.2 \mathrm{~m}^{3}$ per Texan household. While this figure may appear excessive (and expensive) the transition of the electricity industry to renewable energy sources requires significant storage, which should become available at the homes of the consumers or at centralized locations. If there is national mandate (and there is such a goal by the current administration, as in the footnote of page 4) to switch to non-carbon energy sources for the generation of electricity, substantial energy storage will have to become a reality. As mentioned above, high-pressure hydrogen storage technology is available, with several types of commercial vehicles using hydrogen tanks.

Figure 4 shows the hourly variation of the storage capacity throughout the year in TWh and $\mathrm{m}^{3}$ of hydrogen gas.

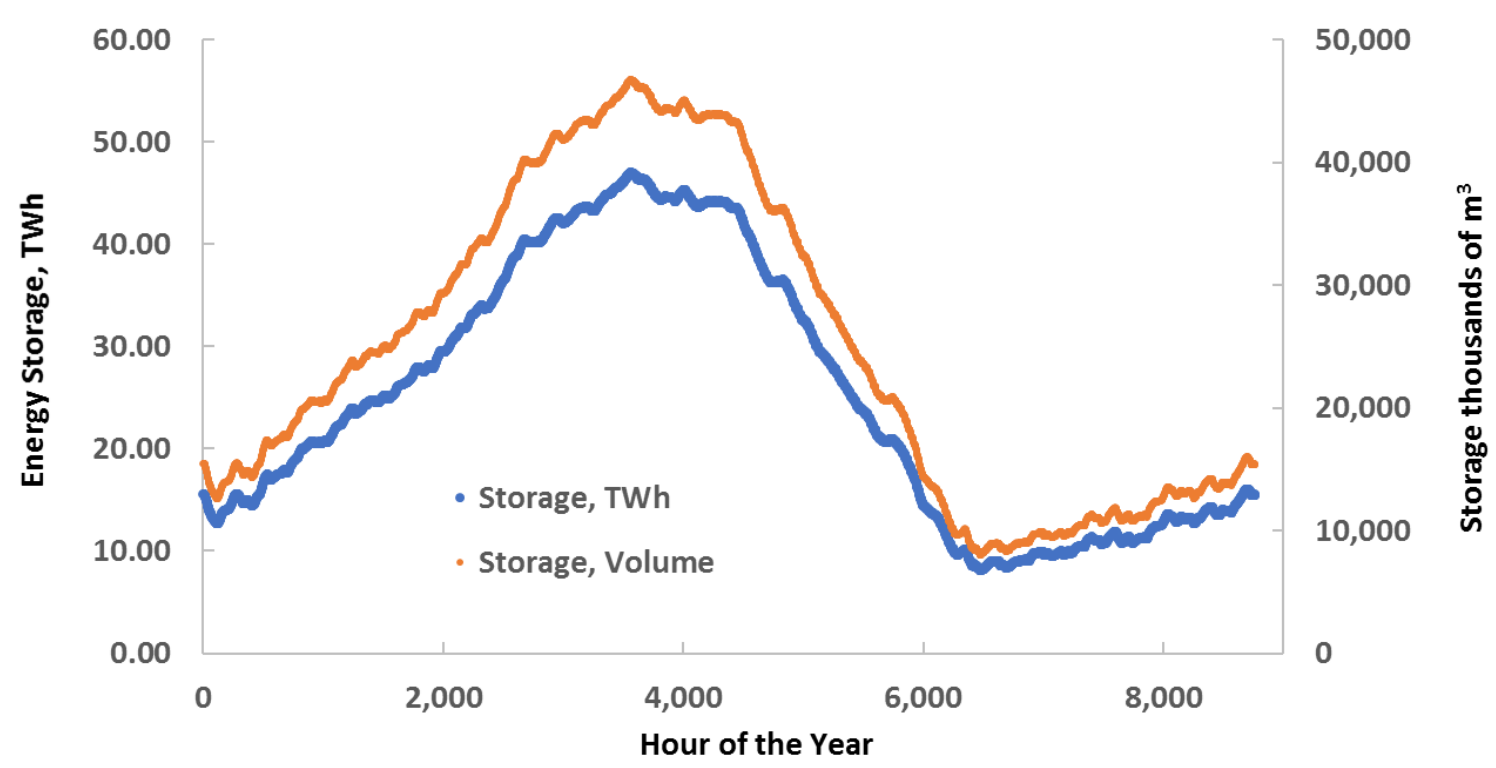

Figure 4 Hourly storage levels for the substitution of all fossil fuel (both coal and natural gas) units with wind power.

It is observed in the data of Figure 4 and Table 2 that the energy storage required for the complete substitution of all the fossil fuel units is significant. The energy storage continuously increases during the winter and spring months; reaches a peak at the end of May where it remains almost constant for about one month; then rapidly decreases in the months July and August (when the hot weather induces high air-conditioning use) to attain its minimum value close to the end of September. From this minimum point, the storage level gradually increases during the autumn months to attain the level it had at the beginning of the year-the hour 1.

Calculations were also performed on the partial substitution of the natural gas units in the ERCOT grid, under the stipulation that all coal units are substituted and nuclear, hydro, and solar units remain at their current level of capacity. Figure 5 shows the additional wind power installed capacity that would be required, when the annual contribution of the natural gas units diminishes from 110 TWh to zero (note that the 2019 contribution of natural gas was $181.8 \mathrm{TWh}$ ). The total wind capacity is equal to the sum of the additional wind capacity and the currently installed capacity. 


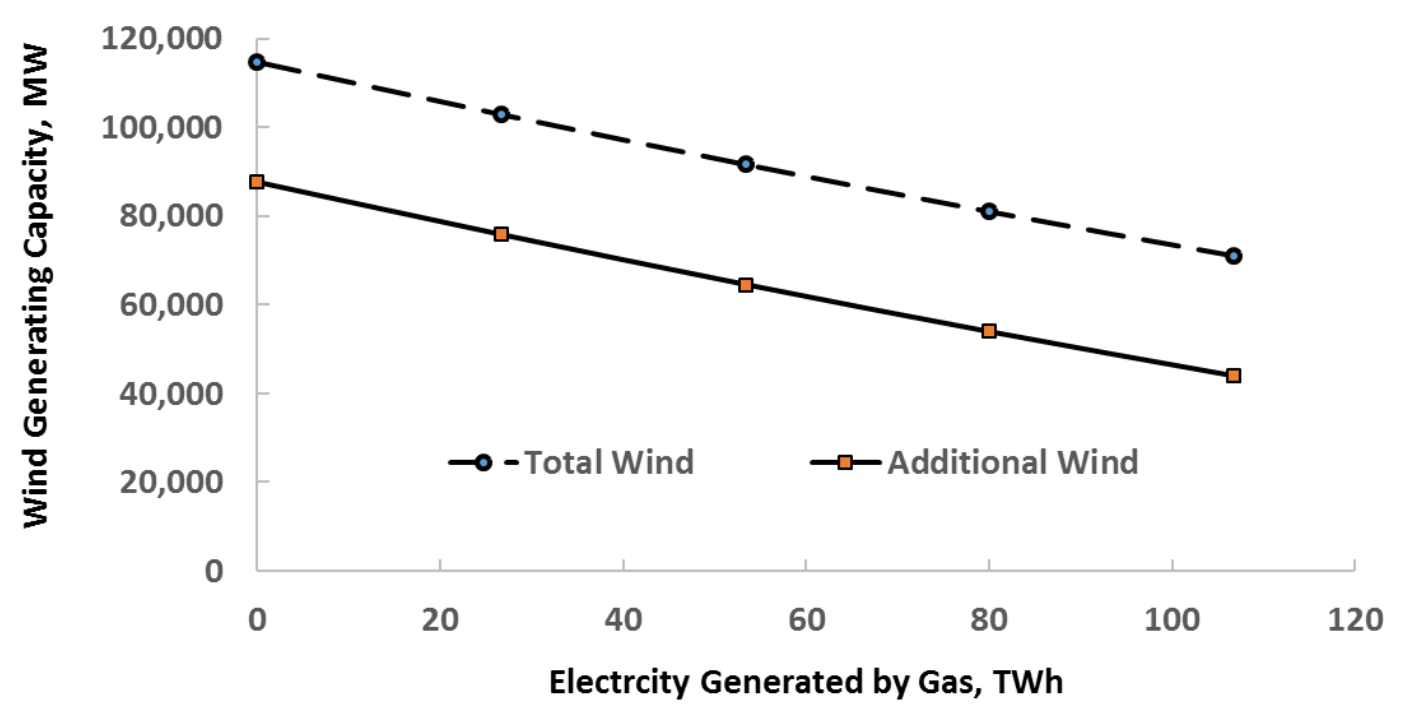

Figure 5 Additional wind power capacity when the annual contribution of the natural gas units decreases to zero.

Figure 6 depicts the storage capacity required, and the annual power dissipation under this partial substitution scenario of all the natural gas units with wind turbines. It is observed in this figure that, dissipation reduction (0.41 TWh per 1 TWh of gas generation) and energy storage reduction (314,000 $\mathrm{m}^{3}$ per $1 \mathrm{TWh}$ of gas generation) may be achieved when a small fraction of the natural gas installations continues to operate. The advantage of the gas installations (gas turbines) is that they may come in-line and taken off-line almost instantaneously and, thus, closely follow the fluctuations of the demand.

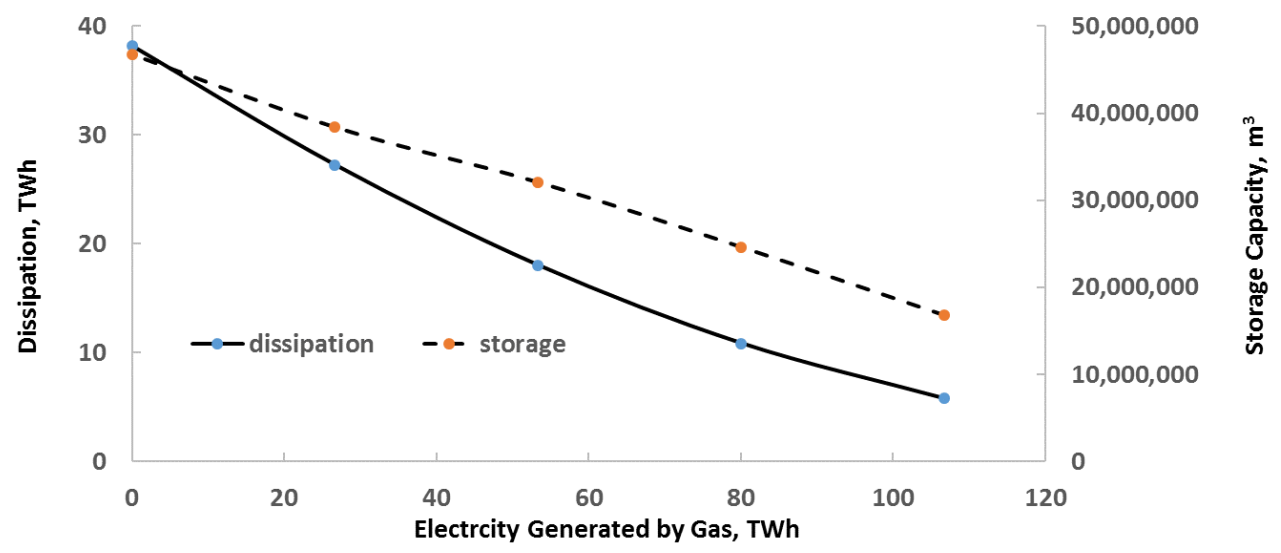

Figure 6 Annual energy dissipation and storage requirements, when the annual contribution of the natural gas units decreases to zero.

\subsection{Effect of Higher Nuclear and Solar Capacity}

The substitution of all fossil fuel units with wind power alone-while keeping the other non-fossil energy sources at their current levels may not be the optimal way to achieve the decarbonization of the electricity generation sector. Further development of the nuclear and solar generation facilities would assist in three ways: 
a) Reducing the needed additional wind power.

b) Reducing the amount of dissipated energy.

c) Reducing the needed energy storage capacity.

Nuclear power plants are base-load units that operate almost continuously throughout the year. Because of this, during a time period, e.g. one year, a nuclear unit produces significantly higher energy than a wind unit of the same rating. Table 3 shows the effect of increasing the nuclear installed capacity from its current level, 4,973 MW, up to five times this current capacity. It is observed that both the energy dissipation and the required hydrogen energy storage decrease significantly. The most beneficial effect is the reduction of the additional wind capacity. The rate of wind-nuclear capacity equivalency is approximately 3 to 1 , consistent with the power operating factor of the wind farms, which is close to $35 \%[5,7,12]$.

Table 3 The effect of additional nuclear installed capacity on the annual energy dissipation, energy storage capacity, and additional installed wind capacity when all fossil fuel units are substituted.

\begin{tabular}{llll}
\hline $\begin{array}{l}\text { Nuclear Installed } \\
\text { Capacity, MW }\end{array}$ & Dissipation, TWh & Storage, $\mathrm{m}^{3}$ & $\begin{array}{l}\text { Additional } \\
\text { Wind, MW }\end{array}$ \\
\hline 4,973 & 38.20 & $46,746,582$ & 87,576 \\
7,460 & 36.41 & $45,956,615$ & 80,192 \\
9,946 & 34.64 & $45,164,529$ & 72,816 \\
14,919 & 31.20 & $43,578,940$ & 58,090 \\
19,892 & 27.91 & $41,049,013$ & 43,414 \\
24,865 & 24.90 & $39,611,191$ & 28,823 \\
\hline
\end{tabular}

Figure 7 shows graphically the effect of additional nuclear generating capacity on energy dissipation and energy storage.

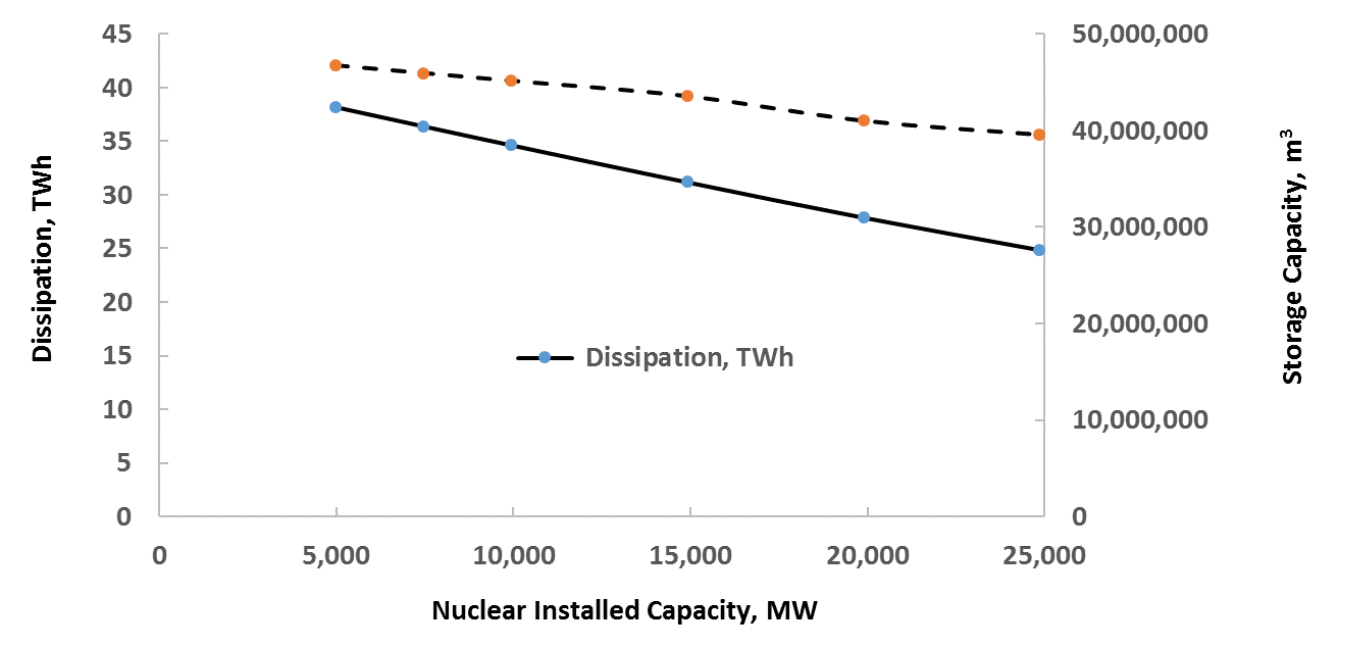

Figure 7 The effect of additional nuclear generating capacity on storage capacity and annually dissipated energy. 
The solar energy substitution effect is different than that of the nuclear effect: solar energy is periodically variable-it is only available during the daylight hours-and is highly correlated with hotter weather-when the air-conditioning systems operate almost continuously, and electricity demand is at its highest. For this reason, it is expected that a small amount of solar-generated electricity would reduce the dissipated energy and the needed storage. Figure 8 depicts the effect of increased solar capacity on the dissipation and storage capacity. The solar generating capacity is given in terms of the percentage of annual electric energy generation, starting at $2.3 \%$, -the current contribution of solar units to the annual energy generated in the grid-to approximately $60 \%$ of the annually generated energy. It is observed that, while the needed storage capacity continuously decreases, the annually dissipated energy attains a minimum at approximately $23 \%$ solar-generated electricity-ten times the solar-generated electricity in 2019.

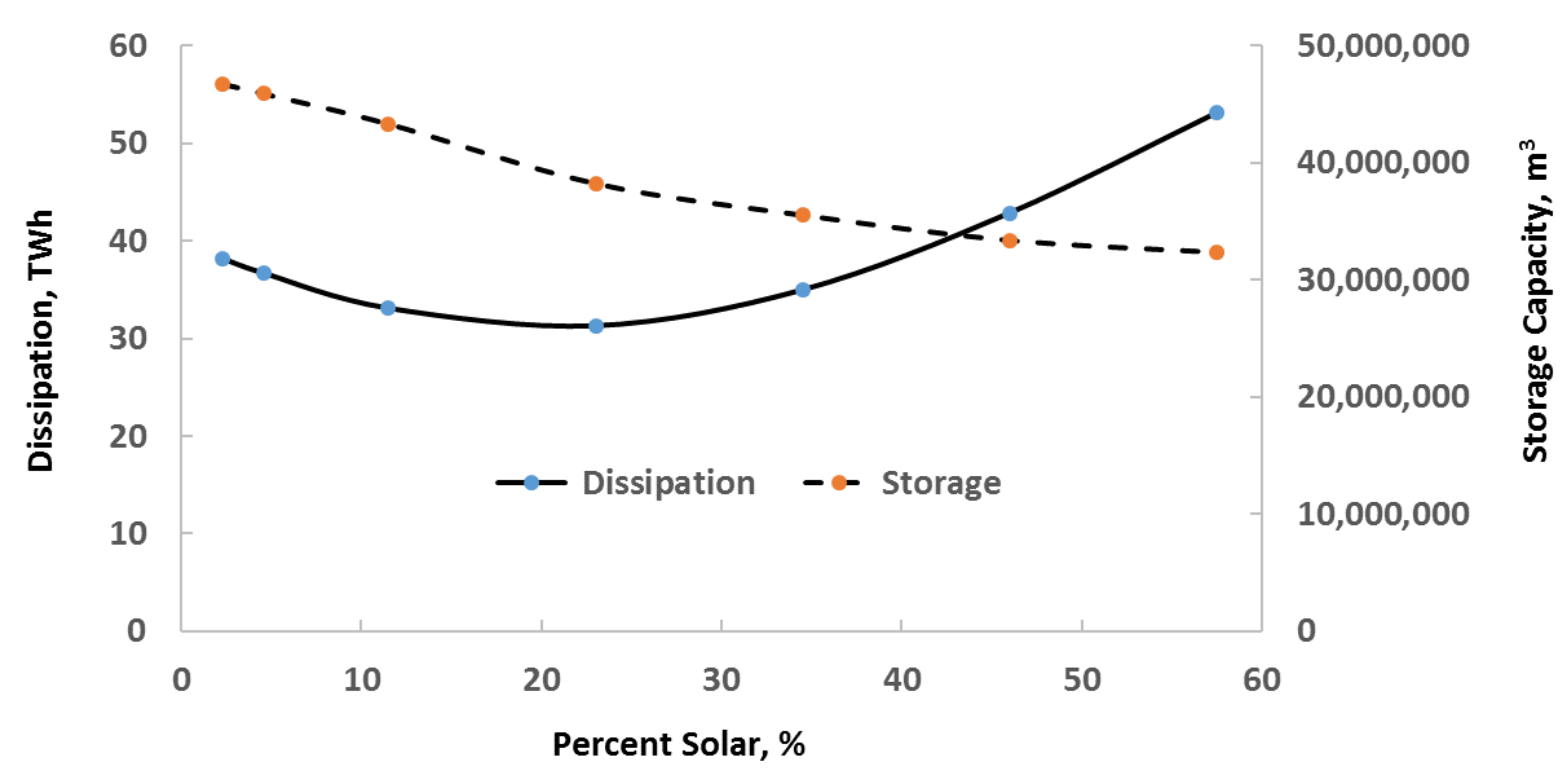

Figure 8 Effect of increased solar installed capacity on the dissipation and energy storage requirements for the substitution of all fossil fuel units.

Figure 9 shows the effect of both nuclear and solar additional generating capacity, in MW, on the additional wind generating capacity for the complete substitution of the fossil fuel power plants. The right-most points of the two curves in Figure 9 represent the currently installed generating capacity of nuclear (4,973 MW) and solar (4,587 MW) in the abscissa, with the needed additional wind capacity $(87,576 \mathrm{MW})$ in the ordinate. A glance at the two curves proves that, for the full substitution of the fossil fuel power plants, the power equivalency of the nuclear units is approximately $3 \mathrm{MW}$ of wind installed power for $1 \mathrm{MW}$ of nuclear installed power; and $0.58 \mathrm{MW}$ of wind installed power for $1 \mathrm{MW}$ of solar installed power. This reflects the lower power operating factors and availability factors of solar installations [5, 7]. 


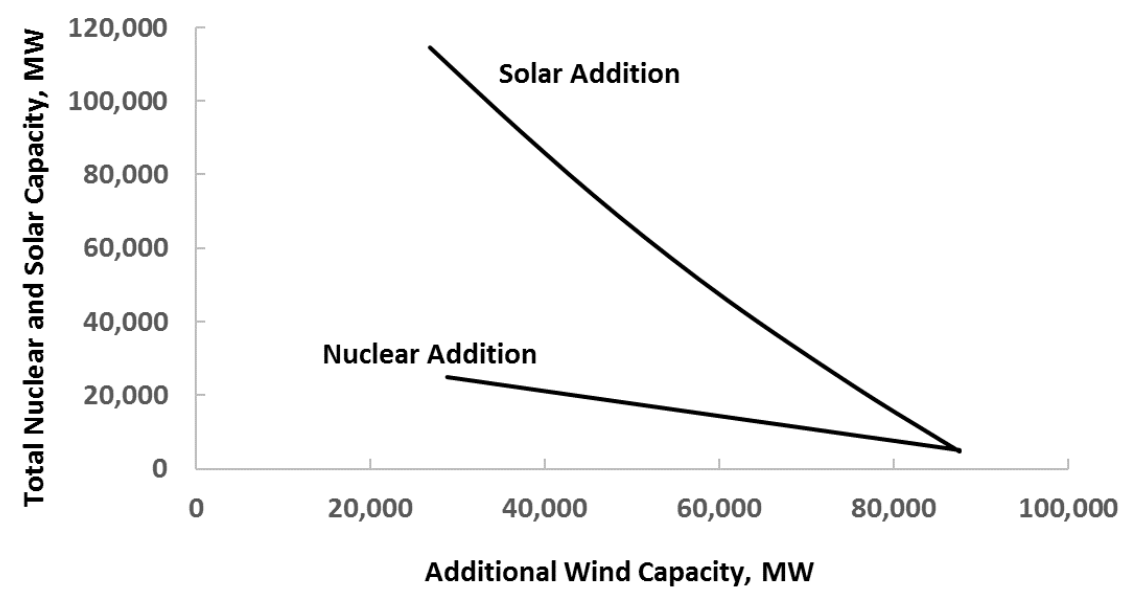

Figure 9 Effect of nuclear and solar generating capacity on the required additional wind capacity for the substitution of all fossil fuel power plants in ERCOT.

It must be noted that the environmental and ecological impacts of nuclear energy (radioactivity in processing the fuel and the waste; risk of an accident; and waste custody and storage over millions of years) are by far more severe than those of the renewable wind and solar energy. It may also be argued that the potential environmental and ecological effects of nuclear energy are significantly more severe than those of coal and natural gas (primarily $\mathrm{CO}_{2}$ emissions). While the environmental and ecological impacts of wind turbines in Texas are minimal (primarily on migrating birds, local noise, and interference with communications) the effects of nuclear energy are significantly higher. The decision to include nuclear energy in the final mix of electric power generation will have to take into account, such environmental and ecological impacts. While there is already a nuclear waste storage facility near the town of Andrews, Texas, the addition of more nuclear power plants in the State may encounter significant opposition.

It must be noted that the transition from fossil fuels to renewable energy sources may be achieved with significant investment that would have to be passed to the consumers. The main areas for investment are summarized as follows:

- Investment in new wind units. Given the power operating factors of wind units, their installed capacity will have to be approximately 3 times higher than the capacity of the coal units they substitute. This investment includes: the cost of the wind turbine itself; planning cost; the cost of the tower; the electrical distribution upgrades; the cost of site works including access roads; and any environmental upgrades cost. Currently such investment costs range from $\$ 1.2$ million to $\$ 5$ million per $\mathrm{MWh}$, with the larger turbines having lower cost.

- If nuclear energy is chosen in the total electricity generation mix, the cost of the nuclear installations-currently at approximately $\$ 9.5$ million per MWh.

- Investment in energy storage. This may be borne by the consumers (e.g. each household will need to be fitted with a hydrogen tank and a system of fuel cells that would store and generate electricity) and should be accounted with the total cost of decarbonization.

- Dissipated energy in the storage-recovery process-we must generate more electricity than the demand. 
- Decommissioning of most fossil fuel units and site clean-up.

- Maintaining several gas turbines throughout the area of the grid and natural gas inventory for reliability and emergencies.

It has been estimated that the cost of these investments, when passed to the consumers, will result in a significant increase of the electricity prices-by a factor between 2.8 and $4.2-$ from the current average price of $\$ 0.113 / \mathrm{kWh}[29,30]$.

\section{Conclusions}

The complete substitution of fossil fuel power plants with the intermittent wind power entails supply-demand mismatches that must be met with energy storage at the utility level. Windgenerated electricity storage and regeneration (two energy conversion processes) are laden with thermodynamic irreversibilities that must be accounted for. Using the hourly electric power demand in ERCOT, calculations are performed to determine the necessary energy storage and resulting dissipation for the conversion of the fossil fuel power plants in Texas with wind power. It is determined that the substitution of the coal power plants with wind units, while keeping the gas turbine installations available, may be achieved without the deployment of energy storage systems -with the addition of 21,700 MW additional wind power. The complete substitution of all the fossil fuel units-coal and natural gas-requires an additional 87,600 MW of wind power and hydrogen energy systems with 45.3 million $\mathrm{m}^{3}$ capacity. The necessary storage capacity, additional wind power, and energy dissipation during the storage-regeneration processes become significantly less with the development of additional nuclear power plants and photovoltaic solar units.

\section{Acknowledgments}

This research was partly supported by the Tex Moncrief Chair of Engineering at TCU.

\section{Author Contributions}

The author did all the research work of this study.

\section{Competing Interests}

The author has declared that no competing interests exist.

\section{References}

1. International Energy Agency. Key world statistics 2020. Paris: IEA-Chirat; 2020.

2. Ruth MF, Zinaman OR, Antkowiak M, Boardman RD, Cherry RS, Bazilian MD. Nuclear-renewable hybrid energy systems: Opportunities, interconnections, and needs. Energy Convers Manag. 2014; 78: 684-694.

3. van der Zwaan BC. Nuclear energy: Tenfold expansion or phase-out? Technol Forecast Soc Change. 2002; 69: 287-307.

4. Michaelides EE. Alternative energy sources. Berlin: Springer; 2012.

5. El-Wakil MM. Power plant technology. New York: McGraw Hill; 1984.

6. Freeman E, Occello D, Barnes F. Energy storage for electrical systems in the USA. AIMS Energy. 
2016; 4: 856-875.

7. Michaelides EE. Energy, the environment, and sustainability. Boca Raton: CRC Press; 2018.

8. Leonard MD, Michaelides EE, Michaelides DN. Energy storage needs for the substitution of fossil fuel power plants with renewables. Renew Energ. 2020; 145: 951-962.

9. Headley AJ, Copp DA. Energy storage sizing for grid compatibility of intermittent renewable resources: A California case study. Energy. 2020; 198: 117310.

10. Cany C, Mansilla C, Mathonnière G, Da Costa P. Nuclear contribution to the penetration of variable renewable energy sources in a French decarbonised power mix. Energy. 2018; 150: 544555.

11. Sato $H$, Yan XL. Study of an HTGR and renewable energy hybrid system for grid stability. Nucl Eng Des. 2019; 343: 178-186.

12. Michaelides EE, Michaelides DN. Impact of nuclear energy on fossil fuel substitution. Nucl Eng Des. 2020; 366: 110742.

13. Huang J, McElroy MB. A 32-year perspective on the origin of wind energy in a warming climate. Renew Energ. 2015; 77: 482-492.

14. Aly AM, Rezaee M. Accelerated controller tuning for wind turbines under multiple hazards. J Energy Power Technol. 2021; 3. Doi:10.21926/jept.2101011.

15. Tapiador FJ. Assessment of renewable energy potential through satellite data and numerical models. Energy Environ Sci. 2009; 2: 1142-1161.

16. De Castro C, Mediavilla M, Miguel LJ, Frechoso F. Global wind power potential: Physical and technological limits. Energy Policy. 2011; 39: 6677-6682.

17. Sailor DJ, Smith M, Hart M. Climate change implications for wind power resources in the Northwest United States. Renew Energ. 2008; 33: 2393-2406.

18. Mai T, Lopez A, Mowers M, Lantz E. Interactions of wind energy project siting, wind resource potential, and the evolution of the US power system. Energy. 2021; 223: 119998.

19. Hsu SA. Nowcasting wind, wave, current and turbulence intensity for offshore wind power operation and maintenance. J Energy Power Technol. 2021; 3. Doi:10.21926/jept.2101014.

20. International Energy Agency. Key world statistics 2019. Paris: IEA-Chirat; 2019.

21. Generation [Internet]. Austin, Texas: Electric Reliability Council of Texas, Inc.; 2021 [cited date 2021 April]. Available from: http://www.ercot.com/gridinfo/generation.

22. China Association for Hydrogen Energy, Engineering Research Center of High Pressure Process Equipment, Safety of the Ministry of Education in China, United States Department of Energy. International hydrogen fuel and pressure vessel forum 2010. Proceedings of the International Hydrogen Fuel and Pressure Vessel Forum 2010; 2010 September 27th-29th; Beijing, China. San Francisco: Internet Archive.

23. Mazloomi K, Sulaiman NB, Moayedi H. Electrical efficiency of electrolytic hydrogen production. Int J Electrochem Sci. 2012; 7: 3314-3326.

24. United States Department of Energy. Hydrogen fuel cell factsheet [Internet]. Washington: United States Department of Energy; 2006. Available from: https://www.californiahydrogen.org/wp-content/uploads/files/doe fuelcell factsheet.pdf.

25. Vestas V90-3.0 [Internet]. Wind-turbine-models; 2021 [cited date 2021 September]. Available from: https://en.wind-turbine-models.com/turbines/603-vestas-v90-3.0.

26. Siemens. Historic contract for turnkey rail system in Egypt [Internet]. Munich: Siemens. Available from: http://www.siemens.com/wind. 
27. Nelson V. Introduction to renewable energy. Boca Raton: CRC Press; 2011.

28. 2020 Long-Term System Assessment for the ERCOT Region. Austin, Texas: Electric Reliability Council of Texas, Inc.; 2020. Available from:

https://www.ercot.com/content/wcm/key documents lists/89026/2020 LTSA Report.zip.

29. Michaelides EE. Fossil fuel substitution with renewables for electricity generation--effects on sustainability goals. Eur J Sustain Dev Res. 2020; 4: em0111.

30. Electric Choice. Electric rates by state [Internet]. Tyler: Eisenbach Consulting LLC.; 2021. Available from: https://www.electricchoice.com/electricity-prices-by-state/.

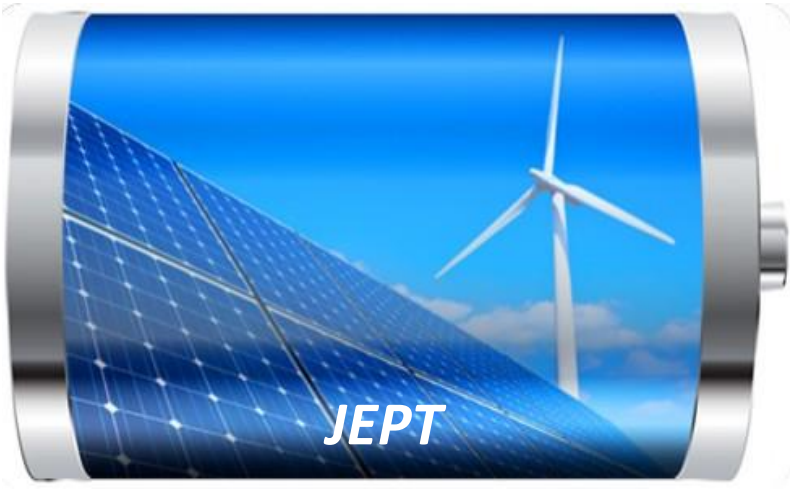

Enjoy JEPT by:

1. Submitting a manuscript

2. Joining in volunteer reviewer bank

3. Joining Editorial Board

4. Guest editing a special issue

For more details, please visit: http://www.lidsen.com/journal/jept 